\title{
Digitalization and Leadership - How Experienced Leaders Interpret Daily Realities in a Digital World
}

\author{
Andreas Hesse \\ EBS University, Oestrich-Winkel, Germany \\ andy.hesse@t-online.de
}

\begin{abstract}
Digitalization brings about great challenges for leaders of business organizations who now have to deal with disruptive changes on the commercial landscape, with data-driven decision making, as well as with new ways of crowd-based working; and with a workforce with ubiquitous access to information and establishing new ways of communication. In this paper, I examine leaders' perspectives on these digitalization-driven developments. Employing a grounded theory approach, I analyzed data from qualitative interviews of 29 experienced business leaders and several observations. Leaders, as a unit of analysis, discuss environmental changes of leadership as well as updated practices of leaders' communication with their followers. In addition, leaders self-report context-transcendence of their individual leadership styles. The insights contribute to a more integrative view of the interplay of digitalization and leadership and to the debate on whether the assumptions of leadership theories of the non-internet era are still valid.
\end{abstract}

\section{Introduction}

"The change in our way of working to a more social collaborative manner is a symbol for the change in our corporate culture. But, that is the soft part. Digitalization for us is more than that: it is disruption and revolution. And for sure, our leadership has been re-invented." (Interview EG)

Given what we know about the impact of digitalization, the question remains how actors can most effectively manage multiple facets of leadership challenges [14]. And given the growing role digital phenomena play in our life and jobs, it is important to answer this question [40]. Beyond the widespread use of the term digitalization, there are a few inquiries that try to capture the nature of digitalization impacts from a leader's perspective [24, 37]. The evidence from consultancy discussion papers mainly builds on the assumption that digitalization is more than a technological trend and it is changing the underlying foundations of leadership directly or indirectly [1, 24].

In building that mosaic, the validity of traditional leadership theories is challenged within different boundaries [14]. This is the case especially for those "new-genre leadership theories" [41] - such as transformational, authentic or servant leadership that still enjoy scholarly and practitioners' confidence [18]. Richter and Wagner [41] point out that "introducing technology as a mediating mechanism between leaders and their followers is likely to alter a number of leadership features." One theoretical starting point of this study is to explore whether digitalization shifts such leadership styles and in doing so, its underlying concepts [1], and whether it expands or alters available leadership practices from the perspectives of those living in that reality: the leaders. Practically, this is of relevance as an input for developing leadership training as well as for setting up digitalization initiatives or strategies within organizations. Moreover, the topic of how leaders should adapt their style or practice of leading is relevant as new competencies might gain importance while others become less critical [37, 38]. Accordingly, the findings may provide another piece of guidance as to how to utilize digital technologies in the service of organizational goals.

Although leadership training and the consulting industry have transposed the phenomenon of leadership in a digital world into digital leadership [37] and leadership 2.0 [41], it has received surprisingly limited scholarly attention $[4,14,24,41$, 43]. A review of the overall literature, which to date has examined both leadership and digitalization, revealed that a significant majority of the research published is composed of practitioner-focused studies by consultants, institutions and associations [17, 29, 49]. Most of these investigations survey perceptual 
data while leaders quantitatively evaluate the importance of digitalization, needs for leadership training, or the use of social media and social software [24].

Nevertheless, we already know a lot about the intersections of technology and organizations. One stream of knowledge focuses on "why individuals adopt new technologies" [50] and how the diffusion of innovations takes place within organizations [42]. In particular Avolio, Kahai and Dodge's work points out the recursive relationship between information technology and organizational settings and bridges it to e-leadership [3, 16]. Further, scholars have focused on virtual teams and have shown how trust and satisfaction can be predicted [43, 53]; how virtual teams perform a distributed leadership [53]; or, how the emergence of transformational leadership can be predicted in virtual teams [6]. In addition, recent studies analyzing the use of social media by political leaders or by grassroots organizations add further understanding [4]. This is of relevance for my study, which focuses on for-profit organizations because the virtuality of teams as well as the use of social media for internal communication campaigns are phenomena that have become more prevalent there as well.

I examine leaders' interpretations of digitalization by interviewing and observing, and analyze that following a grounded theory approach [23]. In doing so, I gain a better understanding of the consequences of digitalization on leadership and I challenge the validity of leadership theories of the past. Due to the exploratory and interpretative nature of my approach, my research question focuses on "how" leaders understand digitalization and leadership rather than testing "whether" or asking "how many" as other studies do. In the same way, my research question is: How do experienced leaders interpret daily leadership realities in a digital world?

\section{Leadership theories related to digitalization}

The starting point of my study is not solely theoretical. Emerging leadership theories related to digitalization act as a guiding stimulus [23]. Starting with a definition of leadership, I subsequently briefly summarize links to leadership research on four dimensions: context, conditions, practices and styles of leadership. The selection of these dimensions was driven, on the one hand, by their emergence during most of the interviews and on the other hand, by observations added later distinguishing the dimensions more clearly in regard to digitalization and leadership.

According to Fiedler's 50-year-old definition, leaders are defined as "the individual in the group given the task of directing and coordinating taskrelevant group activities" [20]. While early leadership research focused on the traits of leaders [45], a later focus was on the behaviors leaders exhibit as well as on situational factors [10, 26, 27].

Context-sensitivity of leadership: 50 years ago, Fiedler [20] built an understanding of a contextsensitive manner of leadership that considers contingencies and determines the right balance of practices to be more effective. As a result, defining leadership today focuses on the process of influence and considers the significance of contextual factors $[8,12]$. It seems important to me to take that into account: "Leadership is a relationship among persons embedded in a social setting at a given historic moment." [9]. Thus, questions are being raised such as: "Is digitalization more than a contextual change?"

Conditions of leadership: Venkatesh et al. [50] complemented more technological studies by adding "social influence" and "facilitating conditions" as variables influencing the intersection between behavioral intention and the use of technology. In 2000 Avolio, Kahai, and Dodge [3] coined the term e-leadership to describe leadership under conditions of dispersed and fluid teams where a significant amount of work is supported by IT. In their seminal paper, they focus on how virtual teams can overcome conditions of distance using computer-mediated communication. Like other authors, they define eleadership as a behavior, the use of electronic media for leadership communication purposes, but they do not discuss underlying theories in-depth [16].

To define the term digitalization multiple perspectives beyond the technical "digitization of analogue data" [44] are required. Gartner [21] defines digitalization with a business-oriented focus: "Digitalization is the use of digital technologies to change a business model and provide new revenue and value-producing opportunities; it is the process of moving to a digital business." Focusing on conditional changes, digitalization in a broader sense refers to "the adoption or increase in the use of digital or computer technology by an organization, industry, or country etc." [11]. However, this phenomenon is not the first high-tech 'trend' to change the world for businesses and their leaders. In regard to conditions of leadership over all, it is important to answer questions like "Do technological trends change the conditions for leadership?" from a leader's perspective. 
Leadership behavior and practices: Following Fiedler [20], leadership behavior can be defined as "the particular acts in which a leader engages in the course of directing and coordinating the work of his group members." and will be used synonymously with leadership practices. It is beyond doubt that technology, IT and thus digitalization have an impact on tasks and practices such as communication, information management, coaching, knowledge management, collaboration, decision making and so forth [25, 52]. Richter and Wagner [41] "define leadership 2.0 as a process of social influence that takes place in an organizational context where a significant amount of work is supported by social software". Thus, the scope of leadership 2.0 concentrates on communication and collaboration practices but in addition, the authors illustrate the role of leaders in the implementation of ESSPs and discuss indirect impacts on leadership. Leadership communication or leaders' communication practices theoretically are focused on communication skills and their outcomes in terms of motivation or trust. Mayfield and Mayfield [32] highlight the importance of "walking the talk" and the congruence of communication and behavior as a crucial success factor of leaders' communication. Along with the "what" that leaders communicate, the choice of communication channels is relevant for the outcome of communication [15]. Moreover, the communication behavior of followers has emerged as a relevant issue within the digital world due to the omnipresence of smartphones, mobile internet and social media. Owners of devices and accounts can easily network, share data, or access news and knowledge. While e-mail, voice over IP, and videoconferencing can be categorized as established ways of computer-mediated communication (or traditional IT), social software as bundles of communication channels are its advanced form, recently customized for enterprise requirements [31]. Thus, questions like "What is the impact of social media use in enterprises on leadership?" are of practical and theoretical relevance for the debate on digitalization and leadership.

Leadership styles: Leadership style is "the underlying need-structure of the individual which motivates his behavior in various leadership situations" [20]. Bass's [8] transformational leadership theory was the starting point for "newgenre leadership" models emphasizing that a leader's style should be visionary, ideological, participative, servant, or authentic [41]. These models revealed that reducing the distance between leaders and their followers while building on cooperation, delegation, participation etc. improves the outcomes of leadership [8]. It is important to illuminate how leaders look on that: Are different leadership styles more appropriate for different tasks [38]? My aim is to challenge these underlying assumptions by discussing with leaders whether digitalization disrupts cornerstones of new-genre leadership theories that have their foundations in the last century.

\section{Methods}

While leadership is one of the most studied fields in organizational sciences, digitalization is a rather young and unexplored phenomenon, which provided an initial reason for my choice of qualitative methods.

In answering the research question, I do not aim to draw conclusions about an objective reality; rather, I seek to gain insight into how various individuals interpret reality [47]. The theoretical links between digitalization and leadership I mentioned previously give an "initial direction in developing relevant categories and properties and in choosing possible modes of integration" [23]. Thus, this study builds a "theoretical explanation by specifying phenomena in terms of conditions that give rise to them, how they are expressed through action/interaction, the consequences that result from them and variations of these qualifiers." [46].

For the sake of clarity, I excluded the perspective of followers to keep the complexity of this study manageable. Moreover, dyadic relationships would have biased the answers due to interpersonal leadermember relations. In doing so, I have lost a related perspective; however, I am aiming for clarity. Nonetheless, I considered the literature regarding followers' perspectives on leadership, especially followership theory and studies concerning the younger generation in working contexts [7, 37, 39].

\subsection{Data collection}

The constitution of the study was iterative, since I did not know what the interviewees would tell me until I talked to them.

In an effort to be open to a wide variety of possible outcomes, maximum variation and theoretical sampling techniques were applied [46]. The sampling of the first block of interviewees was driven by Eisenhardt and Graebner's [19] guidelines for finding interviewees who view the focal phenomena from diverse perspectives. Twenty-nine semi-structured interviews make up the heart of my data. The interviewees were leaders from small, medium and large for-profit enterprises in Germany 
who operated on different hierarchical levels, including the top level and the frontline. For the sake of diversity, I interviewed leaders across 14 industries from 26 enterprises (see Table 1). This decision was driven by the awareness that different industries are in different environments in regard to digitalization challenges [51].

Nevertheless, the sample size does not allow for analyzing characteristics across the interviews. All of the leaders had at least ten years of leadership experience. This sampling rule was purposefully defined to identify respondents who are knowledgeable with regard to leadership development over a longer period, starting from the early days of digitalization. Moreover, I took care to consider gender balance and respondents with various educational backgrounds. To gain insights at the forefront of leadership, I interviewed mainly leaders in operating functions but also included leaders in supporting functions such as HR, quality management and IT as well. That multiplicity of individual contexts of respondents reduces the contextual limits of my study and mitigates the risk of a potential informant bias.

\begin{tabular}{cll}
\multicolumn{3}{c}{ Table 1. List of interviews } \\
\hline No. & Industry & Size \\
\hline 1 & Banking & M \\
4 & Consumer \& packaged goods & L, M, M, M \\
5 & High technology & L, L, L, L, M \\
1 & Insurance & L \\
3 & Manufacturing & L, M, S \\
1 & Pharmaceuticals & L \\
2 & Professional service firms & L, M \\
5 & Retail & L, L, L, M, S \\
3 & Telecommunication & L, L \\
2 & Travel \& hospitality & M, S \\
2 & Utilities & L, M \\
& & Large, Medium, Small \\
\end{tabular}

The topics and issues were specified in advance in an interview-guide (see Appendix), but I decided on the sequence and specific wording of the questions during the interviews. The interviews contained questions about digitalization and its role for the respondent's industry, organization and individual working life. Further, the interviewees provided selfreports of their individual leadership styles, their leadership practices, their views on the development of followers and finally, the use of social media in enterprises.

The interviews took place between December 2015 and March 2016 in the offices of the interviewees and lasted on average around 45 minutes. In that first block of interviews I followed the saturation strategy and finished adding interviews when the last interview could no longer deliver new content. Since the interviews were conducted in German the quotations used in this paper were translated into English.

For the sake of "crystallization" [48] of thoughts and ideas that emerged while reading the interview transcripts and field notes in-depth, further data sources were gathered. These data collection decisions were sampled theoretically and based on ongoing interpretations. I first examined five documents that were incorporated into the interviews, such as a corporate leadership principles brochure in one case or a news magazine article in a second. During that phase (April 2016 - December 2016), I also visited 26 enterprise websites and in some cases social media sites to gain a better understanding of the context of my interview partners. Moreover, I gathered a focus group of four leaders from different hierarchical levels in diverse functions in the high technology industry to get their reflection on first thoughts and ideas. Furthermore, I attended a "Digital Leadership Conference" organized by an HR consultant and a business school. In addition, I attended a "Leadership 4.0 Training" that was organized for leaders in middle management of a telecommunications company. Finally, I conducted two open dialogues with younger start-up founders, one in a professional service firm and one in the high technology industry. The latter dialogues extended "crystallization" and can be understood as "triangulation" since the context of the two founders with regard to age and size of organization was distinctive from the homogeneity of tenure in my first block of interviews [48]. In each of those cases, an extensive observation note was written and added to my data collection. The variety of my data sources generates richness [48] and refers to the complexity of the interplay of digitalization and leadership.

\subsection{Data analysis}

During the phase of data collection, I prepared the data analysis by adding initial impressions, initial ideas about links, and initial questions to the field notes of the interviews. Before I started computeraided analysis, I discussed my preliminary impressions in a colloquium with other researchers. In a next step, I started with a fine-grained reading, after which I defined nodes that clustered significant excerpts from the material in the software. However, my goal was not yet to distill categories; I was primarily collecting codes without viewing the material explicitly across interviews. That raw catalogue revealed a high degree of complexity of interviewees' interpretations, which led me to begin 
considering a structure of the interplay of digitalization and leadership.

As a next step, I cycled between raw material, literature and my sketches. "Member reflections" [48], e.g., the discussion involving a former CHRO and a CEO at a leadership conference, helped me, for instance, to define the leaders' interpretation of the differences between changes in leadership styles or practices. The result of this phase of analysis was a second catalogue of understandings, explanations, and examples of the impact of digitalization, followers' developments and leadership styles and practices from different viewpoints (see Figure 1).

At this stage of my inquiry - structuring categories to $2^{\text {nd }}$ order themes [22] - the need for a more integrative strategy to build a framework for the interplay of digitalization and leadership became clear.

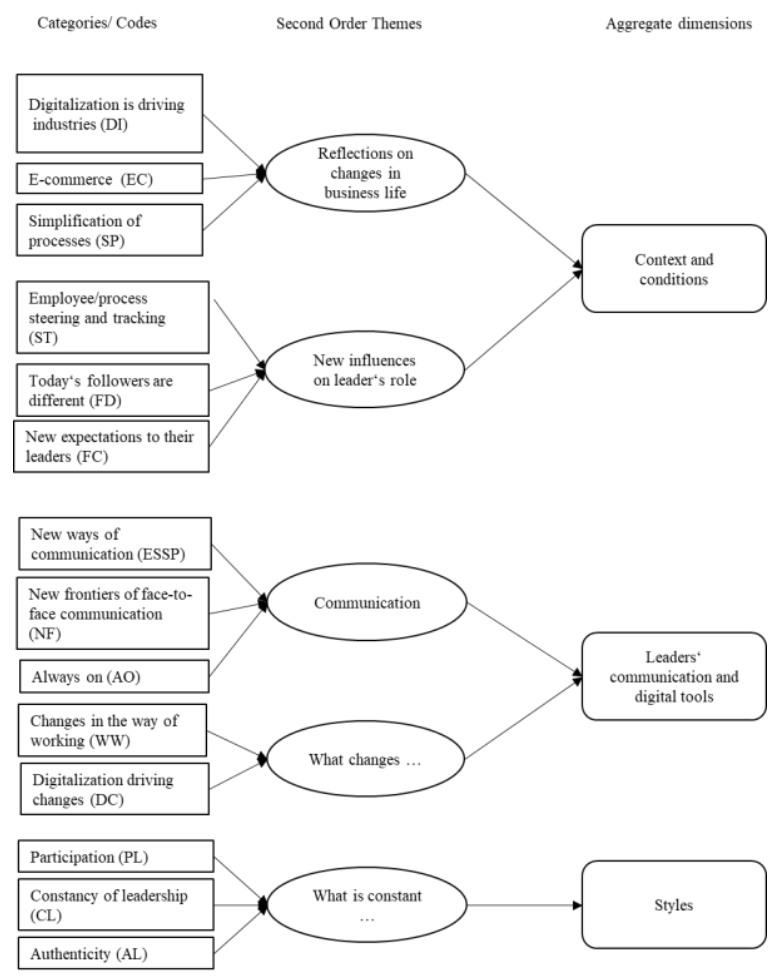

Figure 1. Excerpt of data structure

\section{Findings}

Subsequently, I structurally describe my findings deriving three propositions that frame the interplay of digitalization and leadership. In doing so, digitalization is interpreted as a facilitator of leadership without specifying which kind of leadership outcome is influenced (e.g., team performance, leader-member relationship, employees' satisfaction).

\subsection{Leadership in a digital world}

Context of leadership: Interviewees argued that digitalization has caused various developments in the economic landscape, especially globalized competition and its consequences, e.g., harsh cost reduction programs. Leaders described digitalizationdriven impacts that vary across organizational contexts, in particular, industry backgrounds. Within some industry sectors - e.g., retail - business models are changing in a more disruptive way so that leaders in such industries are confronted and challenged by multiple change management projects. "In the past change management was a task to perform once or twice in a decade: now it is an everyday activity of my job." (Interview WS). Moreover, digitalization enables new levels of transparency, e.g., of business results; it offers ubiquitous internet connectivity and information access as well as devices on an advanced level. "This transformation is so intense and comprehensive, not just in one field. Something like this has never taken place before" (Interview MP). Some interview partners emphasized that a new availability for business tasks or assignments has had as a consequence that they find themselves under increasing pressure. "In the 80's leisure time and working hours were strictly separated - today they are highly intertwined and incoming messages are a pain for me." (Interview SD). Furthermore, they described how especially the younger employees are establishing social media as their favorite private communication channel and thus have selected their own peer-to-peer channel of communication: "All of our teams use WhatsApp groups for informal chats and alignment of activities." (Interview MH).

Conditions of leadership: Furthermore, interviewees discussed developments with a more direct influence on leadership. For instance, monitoring data increases the "ability to control and observe employees" (Interview DA) on the one hand, and options for an authentic leadership style, for instance, by sharing daily activity reports, on the other hand. According to the self-reports of the interviewees, relationships between leaders and their followers are changing compared to the past. Driven by competition, they are facing more virtual, dispersed teams, and within these teams, new interdependencies emerge based on digitalization trends: "Digitalization democratizes information. Access to knowledge changes bargaining power. Power and interdependencies change. There is less hierarchical distance between leaders and members." 
(Interview GJ). Consequently, leaders indicated that they feel that they are encountering well-informed, better educated employees at eye-level who request task delegation and co-creation. In connection with that, younger followers are described as having no experience with and no access to hierarchical behavior, attitudes and policies. "Information for them is at their fingertips, they do not consider information as a source of power. I think that explains a bit why they are not used to hierarchies." (Interview WS). Moreover, in a few cases, I had the impression from the office and workplace situation where the interviews took place that the workplaces were more traditionally "closed", "protected" by secretaries and a kind of leader's privacy space (Field notes interview EG, OF, PK).

Proposition 1: Digitalization moderates the influence of contextual and conditional changes on the outcome of leadership.

For instance, leaders describe the digitalization of businesses and a democratized accessibility of information and knowledge for their followers as changing circumstances.

\subsection{Leaders' communication and digital tools}

For the interview partners, in addition to conditional and contextual changes, the substitution of paper-based communication and oral face-to-face communication by digital forms of communication (focused on texting) is what can be understood as the "digital" of digital leadership (Interview MD, Observation LT). "Compared to the past, I still meet people - be it colleagues or followers - during the whole work day. But additionally, I write e-mails or messages and in doing so, I can keep in touch with by far more people in an ad-hoc-manner." (Interview DW). Quite a few interviewees argued for the importance of keeping face-to-face communication due to the emotional and nonverbal cues involved. The same group perceived too much nonpersonal interaction in leader-member relations as a problem. 'Leaders' tasks are mainly information dissemination, communication and decision-making. Communication should be face-to-face and computer-mediated both ways have their pros and cons. Personal conversations and meetings are often overloaded, unstructured and actions are too often caused by impulse. Social software can support that with completeness, structure, archives, summaries, exchange of feedback and so forth." (Interview MF).

Focusing on the data, a few interviewees clearly defined individual thresholds and limitations regarding the question of what content is appropriate for discussion using digital communication (e.g., personal issues like low performance or salary). Some interviewees indicated that such thresholds are redefined by younger followers: "They even clarify conflicts via WhatsApp while sitting in the same room." (Interview MD).

Especially those leaders who described themselves as tech-savvy and who work in industries that are closer to digitalization, like telecommunication and high technology, highlighted their first user experiences with enterprise social software platforms (ESSPs). For most of them, ESSPs were a more informal communication tool with broad capabilities that have not yet been utilized for their individual leadership tasks: "Being a little cautious here, it is a soft channel for exchanging interesting job-related ideas" (Interview EG). What is viewed as most promising in practice is digitizing routine tasks like agenda management or meeting minutes and the two-way exchange of information in dispersed leader-member settings. The latter aspect was connected to one leader's description of his or her personal leadership style. "I like the digital stuff because my team is empowered to participate. Not all of them join our discussions, but they could." (Interview MF). Since there was still some ambiguity as to whether digital tools are more than what followers use as their favorite communication channel, I discussed that topic with two start-up founders. "Leadership isn't such a big deal since we collaborate in the team on an even playing field. For sure, we use social collaboration and networking tools for all kinds of work. Why should we use different tools for leadership purposes?" (Dialogue SJ). Similarly, I interpret leaders' experiences and their arguments regarding the pros and cons of ESSPs as a step toward the use of digital communication tools for leadership purposes.

Proposition 2: Digitalization facilitates leaders' communication practices and thus affects the outcome of leadership.

Leaders describe that leadership increasingly occurs with computer-mediated communication but is primarily still based on e-mail communication. Moreover, in a testing phase leaders are utilizing ESSPs as a means of leadership instruments.

\subsection{Leadership styles}

With two exceptions (two individuals who emphasized their authoritarian, hierarchical style, both from the travel and hospitality industry), most of the interviewees saw themselves as conducting a servant, participative, or cooperative leadership style influenced by situational factors: "I delegate and align tasks, but how they do [the team does] it is their 
responsibility. My role is to enable them." (Interview $\mathrm{MH})$. Delegation of responsibilities was mentioned as a common element of their leadership styles. Few interviewees described changes in characteristics of their leadership style as compared to the 1990s and a few of that group blamed this change on digitalization. However, even in a volatile environment with new boundaries, conditions and changing practices, leadership styles were selfreported as context-transcendent: "My way of communicating changed, ok. But not my style of leading people. That has nothing to do with digitalization." (Interview MF). Since this finding contradicted, to some degree, the rest of the findings, I discussed it in a focus group to further understand the differences between leadership practices, leadership styles or leadership behaviors, which were not explicitly differentiated throughout the interviews by the leaders. For two participants, the reported stability was not unexpected since leadership styles have "a long history of surviving the volatility of contexts. In the $80 \mathrm{~s}$ and $90 \mathrm{~s}$ we were facing computerization, now its digitalization" (Observation SL) and are sustainable: "Behavior is to be adapted first. My individual style is resilient and may change, but that takes a long time." (Focus-group SL).

Proposition 3: Digitalization has no tangible impact on the relationship between leadership styles and leadership outcomes.

Thus, I acknowledge that leaders expressed the feeling that their individual leadership styles were not impacted by digitalization. I later discuss alternative explanations for this response of leaders.

\section{Discussion}

Focusing my findings on two core arguments, I will discuss the structure of a framework for the interplay of digitalization and leadership, and the validity of assumptions of new-genre leadership theories in the digital era.

\subsection{Toward a more integrative approach to building a framework for the interplay of digitalization and leadership}

As early as ten years ago, Avolio [2] called for a next level of integration, "taking into account the prior, current, and emerging context - for continued progress to be made in advancing both the science and practice of leadership." In his terminology, he differentiates between the "proximal" context that leaders are embedded in and the "distal" context that comprises the broader social-cultural environment as elements that constitute an emergent leadership theory [2]. My examination reveals similar elements of a framework - contextual influences (distal context) and specific conditions (proximal context). Moreover, I add everyday behavioral elements and practices of leaders' communications to the emerging framework for the interplay of digitalization and leadership. Using ESSPs offers new ways of interaction, authenticity and overcoming the obstructions inherent in a dispersed setting. Theoretically, my empirical work is new with respect to the exclusive qualitative leaders' perspective. Accordingly, I add value by demonstrating the complexity of the interplay of digitalization and leadership. Moreover, the scope of this framework complements the scope of the definitions of eleadership, digital leadership or leadership 2.0 as my original theoretical motivation [3, 37, 41].

\subsection{Participation and authenticity as bridges between digitalization and leadership}

Following this integrative approach to building a framework, the validity of new-genre leadership theories may also be discussed [43]. In building on the leaders' interpretations and my observations, I use two trains of thought in my explanation.

First, iterating between data collection and the literature, I encountered participation, on the one hand, as a characteristic of digital tools as a means of communication and delegation (empirical perspective) and on the other hand, as an element of the path-goal theory of leadership (theory perspective). In their seminal article, House and Mitchell [27] explain why participative leadership has a positive impact on performance: "More specifically, when people participate in the decision process they become more ego-involved, the decisions made are in some part their own." Leaders, especially those working in industries that are advanced in digitalization like telecommunication or high technology, emphasized the fact that social software encourages feedback, enables the delegation of routine tasks and involves followers. Similarly, Avolio and Kahai [5] indicate that participative " $\mathrm{e}$ leaders ... may set up chat rooms to solicit opinions from members of a global virtual team before making any final decision." Followers are described in the data as no longer being obedient or passive: "While they are filled with knowledge, they are encouraged to take on responsibilities" (Interview MD). This is congruent with a number of theoretical perspectives on followership describing followers as wanting to influence, change and alter their environment in the way they see it [7]. This congruence of participation 
as an underlying concept is one interpretation of the instance of leaders reflecting on stability in their individual leadership style while they discuss contextual, conditional and behavioral changes. The stability of leadership style within an organizational environment of change contradicts what Biggart and Hamilton [9] labeled 30 years ago as the institutional theory of leadership while proposing that "as an organization changes over time the strategies of leadership will also change."

O'Reilly [36] built his concept of Web 2.0 on its characteristic of user-generated content. The participation of users, customers, followers, or employees underlies this concept, which was later labeled as an "architecture of participation" [33] and a "participatory system" [4]. Social media and ESSPs facilitate such participative use [28] and thus can promote "participative" leadership, as highlighted in the interviews. Avolio et al. [3] emphasized such a kind of consistency between leadership spirit (e.g., participative) and IT spirit as being important for "faithful appropriations" [3].

Just as in my argumentation regarding participation, I outline a second bridge between digitalization and leadership with transparency and authenticity. Digitalization enables leaders to act in a transparent manner, for instance, to sharing activities and emotions and thus performing authentic leadership. Similarly, authenticity can be identified as a common element of new-genre leadership models and the framework of leadership and digitalization [41]. However, Colbert, Yee and George [14] discuss concerns for a reduced authenticity driven by digitalization in terms of less face-to-face communication and interactions characterized by less fully present participants.

All in all, I conclude that following the qualitative interpretations of the interviewed leaders, I confirm the validity of the underlying assumptions of newgenre leadership theories, in particular participation and authenticity. Thus, self-reports of changes of context, conditions and practices do not yield a new leadership paradigm or model.

\subsection{Limitations and further research}

Grounded theory rarely has interviews as its sole form of data collection [23]. Interviews are selfreports in one moment in time, in one individual situation embedded in various contexts. That is why I rely on interviews, on the one hand, to understand leaders' interpretations of daily real life, and that is why I sampled the interviewees, aiming for a wide variety of backgrounds, industries, functions and variety in gender on the other hand. To mitigate the risk of relying solely on interviews, I purposefully gathered further data in observations and documents.

In addition, I focus on the validity of the finding of stable leadership styles. Most respondents claimed their individual leadership style as resistant and not impacted by digitalization. This may be the case if they do not want to admit changes since a sustainable leadership style can be seen as more socially desirable. Knights and Willmott [30] note that managers in general try to secure a sense of stability and certainty in a "destabilized working world". However, sustaining leadership styles can be seen as sustainable personality traits of leaders [34]. Although there are some critiques of trait-centered theories of leadership [45], the context-transcendence of self-reported leadership styles in my study confirms the idea of the sustainability of personal traits. Moreover, due to the longitudinal retrospective consideration, it may be that the respondents simply do not perceive gradual changes of their individual leadership style over time.

The latter discussion leads me to an avenue for future scholarly work: Researchers could complement my approach by adding the qualitative perspective of followers. How do followers interpret daily realities in a digital world? Whether and how do especially experienced followers see changes in the leadership context, conditions, practices and styles?

\section{Conclusion}

Digitalization is transforming businesses and, by the same token, the context and conditions for leadership in a digital world. My study deepens our understanding of digitalization and leadership by adding qualitative perspectives of various leader individuals across industries and functions. Building on that data set I structure various influences, intersections and relations into a framework of digitalization and leadership.

The findings are relevant first for leaders, offering them a more integrative understanding of leadership in a digital world. Categorizing the use of digital tools as new leadership practices enabling leaders to promote participation is of practical relevance as well since the use of such tools is increasingly becoming the norm in a large number of industries [13]. However, does all this yield a new leadership theory, model or paradigm? No, or, more precisely, not yet. Nevertheless, interpreting the comments and thoughts of those who lead on an everyday basis demonstrates the multifaceted nature of the interplay of digitalization and leadership. It is of particular relevance since information systems research and the field of organizational behavior, especially leadership 
research, are both interested in a better understanding of how technology precisely influences humans and organizations.

\section{References}

[1] Alvesson, M. and J. Sandberg, "Generating Research Questions through Problematization", Academy of Management Review, 36(2), 2011, pp. 247-271.

[2] Avolio, B. J., "Promoting more Integrative Strategies for Leadership Theory-Building", American Psychologist, 62(1), 2007, pp. 25-33.

[3] Avolio, B. J., Kahai, S., and G. E. Dodge, "ELeadership: Implications for Theory, Research, and Practice”, The Leadership Quarterly, 11(4), 2000, pp. 615-668.

[4] Avolio, B. J., Sosik, J. J., Kahai, S. S., and B. Baker, "Re-examining Transformations in Leadership Source and Transmission", The Leadership Quarterly, 25(1), 2014, pp. 105-131.

[5] Avolio, B. J. and S. S. Kahai, "Adding the ,e' to eLeadership: How it may Impact your Leadership", Organizational Dynamics, 31(4), 2013, pp. 325-338.

[6] Balthazard, P. L., Waldman, D. A., and J. E. Warren, "Predictors of the emergence of transformational leadership in virtual decision teams", The Leadership Quarterly, 20(5), 2009, pp. 651-663.

[7] Baker, S., "The Followership Foundation of a Contemporary Construct", Journal of Leadership and Organizational Studies, 14(1), 2007, pp. 50-60.

[8] Bass, B. M., Leadership and Performance Beyond Expectations, New York: Free Press, 1985.

[9] Biggart, N. W. and G. G. Hamilton, "An Institutional Theory of Leadership", Journal of Applied Behavioral Science, 23(4), 1987, pp. 429-441.

[10] Blake, R. R. and J. S. Mouton. The Managerial Grid. Houston, TX: Gulf Publishing Company, 1964.

[11] Brennen, S. and D. Kreiss, 2014, "Digitalization and Digitalization". Retrieved December 6, 2015, from http://culturedigitally.org/2014/09/digitalization-anddigitalization

[12] Bryman, A., Stephens, M., and C. á Campo, "The Importance of Context: Qualitative Research and the Study of Leadership", The Leadership Quarterly, 7(3), 1996, pp. 353-370.

[13] Bughin, J., Chui, M., and L. Pollak, 2013. "Organizing for Change Through Social Technologies: McKinsey Global Survey Results. Retrieved August 15, 2015, from www.mckinseyquarterly.com

[14] Colbert, A., Yee, N., and G. George, "The Digital Workforce and the Workplace of the Future", Academy of Management Journal, 59(3), 2016, pp. 731-739.

[15] Daft, R. L. and R. H. Lengel, "Organizational Information Requirements, Media Richness and Structural Design", Management Science, 32(5), 1986, pp. 554-571.

[16] DasGupta, P., "Literature Review: E-Leadership",
Emerging Leadership Journeys, 4(1), 2011, pp. 1-36.

[17] Depiereux, P., "Digital Transformation und Zusammenarbeit mit Startups in Großunternehmen in Deutschland und den USA " [Digital Transformation and Collaboration with Start-ups by Corporations in Germany and USA], Retrieved May 5, 2017, from: https://www.etventure.de/innovationsstudien

[18] Dinh, J. E., Lord, R. G., Gardner, W. L., Meuser, J. D., Liden, R. C., and J. Hu, „Leadership Theory and Research in the New Millennium: Current Theoretical Trends and Changing Perspectives", The Leadership Quarterly, 25 (1), 2014, pp. 36-62.

[19] Eisenhardt, K. M. and M. E. Graebner, "Theory Building from Cases: Opportunities and Challenges", Academy of Management Journal, 50(1), 2007, pp. 2532.

[20] Fiedler, F. E., A Theory of Leadership Effectiveness, McGraw-Hill, New York, 1967.

[21] Gartner IT-Glossary, "Digitalization", 2015. Retrieved August 23, 2017, from www.gartner.com/itglossary/digitalization

[22] Gioia, D. A., Corley, K. G., and A. L. Hamilton, "Seeking Qualitative Rigor in Inductive Research Notes on the Gioia Methodology", Organizational Research Methods, 16(1), 2013, pp. 15-31.

[23] Glaser, B. G. and A. Strauss, The Discovery of Grounded Theory. Aldine de Gruyter, New York, 1967.

[24] Gurr, D., "E-Leadership", in: Encyclopedia of Virtual Communities and Technologies, IGI Global, 2006, pp. 161-165.

[25] Haas, M. R., Criscuolo, P., and G. George, "Which Problems to Solve? Online Knowledge Sharing and Attention Allocation in Organizations", Academy of Management Journal, 58(3), 2015, pp. 680-711.

[26] Hersey, P. and K. H. Blanchard, "Life Cycle Theory of Leadership". Training \& Development Journal, 1969.

[27] House, R. J. and T. R. Mitchell. "Path-Goal Theory of Leadership", No. TR-75-67, Washington University Seattle Department of Psychology, 1975.

[28] Kane, G. C., Alavi, M., Labianca, G., and S. P. Borgatti, "What's Different about Social Media Networks? A Framework and Research Agenda", Forthcoming at MIS Quarterly.

[29] Kasten, J. and M.-R. Diehl, 2017, "Leadership in der digitalen Welt - wo stehen die deutschen Unternehmen [Leadership in the Digital World - What About German Enterprises?]. Retrieved May 18, 2017, from: http://www.boyden.de

[30] Knights, D. and H. Willmott, 'Power and Subjectivity at Work', Sociology, 23(4), 1989, pp. 535-558.

[31] Leonardi, P. M., Huysman, M., and C. Steinfield, "Enterprise Social Media: Definition, History, and Prospects for the Study of Social Technologies in Organizations", Journal of Computer-Mediated Communication, 19(1), 2013, pp. 1-19.

[32] Mayfield, J. and M. Mayfield, "Leader Communication Strategies Critical Paths to Improving 
Employee Commitment", American Business Review, 20(2), 2002, pp. 89-94.

[33] McAfee, A. P., "Enterprise 2.0: The Dawn of Emergent Collaboration", MIT Sloan Management Review, 47(3), 2006, pp. 21-28.

[34] McCrae, R. R. and P. T. Costa, "Validation of the five-factor model of personality across instruments and observers", Journal of Personality and Social Psychology 52(1), 1987, p. 81-90.

[35] Novak, D. and M. C. Bocarnea, "Leading Virtual Teams", IGI Global, 2008, pp. 1-7.

[36] O'Reilly, T., 2005, "What Is Web 2.0. Design Patterns and Business Models for the Next Generation of Software", Retrieved May 17, 2017, http://www.oreilly.com/pub/a/web2/archive/what-isweb-20.html

[37] Petry, T., "Digital Leadership - Unternehmens- und Personalführung in der Digital Economy" [Digital Leadership - Management and Leadership in the Digital Economy], In: T. Petry (Ed.): Digital Leadership (pp. 21-82), Haufe, Freiburg, 2016.

[38] Phelps, K. C., "'So much technology, so little talent?' Skills for harnessing technology for leadership outcomes", Journal of Leadership Studies, 8(2), 2014, pp. 51-56.

[39] Prensky, M., "Digital Natives, Digital Immigrants Part 1", On the Horizon, 9(5), 2001, pp. 1-5.

[40] Richter, A., Hetmank, C., Klier, J., Klier, M., and M. Müller, "Enterprise Social Networks from a Manager's Perspective", in: System Sciences, 49th Hawaii International Conference, 2016, pp. 4242-4251.

[41] Richter, A. and D. Wagner, "Leadership 2.0: Engaging and Supporting Leaders in the Transition Towards a Networked Organization", in: Proceedings of the 47th Hawaii International Conference on System Sciences, 2014.

[42] Rogers, E. M.. Diffusion of Innovations, 5th ed., NY, London, Toronto, Sidney: Free Press, 2010.

[43] Savolainen, T., "Trust-building in e-leadership: A case study of leaders' challenges and skills in technology-mediated interaction", The Journal of Global Business Issues, 8(2), 2014, pp. 45-56.

[44] Schmidt, R., Zimmermann, A., Möhring, M., Nurcan, S., Keller, B. and F. Bär, "Digitization-perspectives for conceptualization", in: European Conference on Service-Oriented and Cloud Computing, 2015, September, pp. 263-275.

[45] Stogdill, R. M., "Personal Factors Associated with Leadership: A Survey of the Literature". The Journal of Psychology, 25(1), 1948, pp. 35-71.

[46] Strauss, A. and J. M. Corbin, "Grounded Theory Research: Procedures, Canons, and Evaluative Criteria", Qualitative Sociology, 13(1), 1990, pp. 3-21.

[47] Suddaby, R., "From the Editors: What Grounded Theory is not", Academy of Management Journal, 49(4), 2006, pp. 633-642.

[48] Tracy, S. J., 'Qualitative Quality: Eight ,Big-Tent' Criteria for Excellent Qualitative Research",
Qualitative Inquiry, 16(10), 2010, pp. 837-851.

[49] van Dick, R., Helfritz, K. H., Stickling, E., Gross, M., and F. Holz, 2016, "Digital Leadership - Die Zukunft der Führung in Unternehmen" [Digital Leadership The Future of Leadership in Enterprises] Retrieved May 5, 2017 from: www.psychologie.unifrankfurt.de/62788532/Digital-Leadership-Studie.pdf

[50] Venkatesh, V., Morris, M. G., Davis, G. B. and F. D. Davis, "User Acceptance of Information Technology: Toward a Unified View”, MIS Quarterly, 2003, 27(3), pp. 425-478.

[51] Westerman, G., Tannou, M., Bonnet, D., Ferraris, P., and A. McAfee, "The Digital Advantage: How Digital Leaders Outperform Their Peers in Every Industry", MIT Sloan Management and Capgemini Consulting, 2013, pp. 2-23.

[52] Zhao, D., Zuo, M., and X. Deng, "Examining the Factors Influencing Cross-Project Knowledge Transfer: An Empirical Study of IT Services Firms in China", International Journal of Project Management, 33(2), 2015, pp. 325-340.

[53] Zigurs, I., "Ledership in virtual teams: Oxymoron or Opportunity?", Organizational Dynamics, 31(4), 2013, pp. 339-351.

\section{Appendix}

Interview Guide
General changes
Opening question: What does digitalization mean for
your industry?
What does digitalization mean for your company?
How do you feel in the digital era?
Leadership
What is important for you as a leader?
What does digitalization mean for you in your role as a
leader?
Has digitalization brought about changes of followers
expectations?
Do you have a concrete example in mind in which
digitalization influenced your leadership style?
Digitalization
What does digitalization mean for your personal
communication behavior in private/in job?
How much do you personally use the social software
platforms (if applicable)?
What does digitalization mean for your way of working
specifically with regards to communication?
What is your experience using the enterprise social
software?
End
Do you recognize any further changes in further areas
with regard to digitalization?
How do you think digitalization will influence
leadership in the future?
Statistics
Age, gender, industry, function, educational background,
working experience, experience with social media and
social software, number of subordinates, management
level

